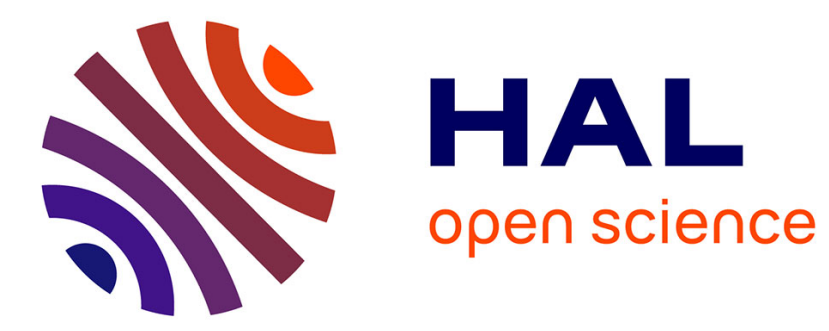

\title{
Iron-Catalyzed Silylation of Alcohols by Transfer Hydrosilylation with Silyl Formates
}

Timothé Godou, Clément Chauvier, Pierre Thuéry, Thibault Cantat

\section{To cite this version:}

Timothé Godou, Clément Chauvier, Pierre Thuéry, Thibault Cantat. Iron-Catalyzed Silylation of Alcohols by Transfer Hydrosilylation with Silyl Formates. SYNLETT, 2017, 28, pp.A-E. 10.1055/s0036-1591508 . cea-01621212

\section{HAL Id: cea-01621212 https://hal-cea.archives-ouvertes.fr/cea-01621212}

Submitted on 31 Jan 2019

HAL is a multi-disciplinary open access archive for the deposit and dissemination of scientific research documents, whether they are published or not. The documents may come from teaching and research institutions in France or abroad, or from public or private research centers.
L'archive ouverte pluridisciplinaire HAL, est destinée au dépôt et à la diffusion de documents scientifiques de niveau recherche, publiés ou non, émanant des établissements d'enseignement et de recherche français ou étrangers, des laboratoires publics ou privés. 


\section{Iron-Catalyzed Silylation of Alcohols by Transfer Hydrosilylation with Silyl Formates}

\author{
Timothé Godou \\ Clément Chauvier \\ Pierre Thuéry \\ Thibault Cantat*a \\ ${ }^{a}$ NIMBE, CEA, CNRS, Université Paris-Saclay, 91191 Gif-sur- \\ Yvette Cedex, France \\ * indicates the main/corresponding author. \\ thibault.cantat@cea.fr
}

Click here to insert a dedication.<smiles>[R]O[13CH2]O[13CH2]O</smiles>

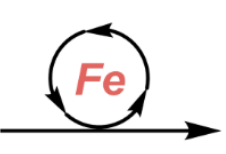

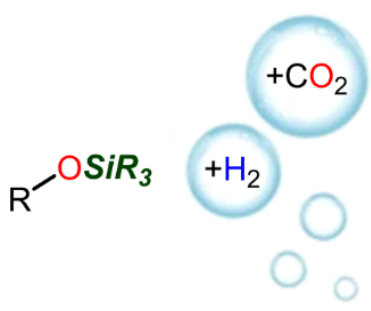

\section{Received:
Accepted:
Published online:}

Abstract An iron catalyst is shown for the first time to promote transfer hydrosilylation with silyl formates and utilized for the silylation of alcohols. Attractive features of this protocol include the use of an earth abundant transition metal catalyst, mild reaction conditions and the release of gases as the only by-products $\left(\mathrm{H}_{2}\right.$ and $\left.\mathrm{CO}_{2}\right)$.

Key words silylation, iron catalysis, silanes, alcohols, silyl formates, hydrosilanes, $\mathrm{CO}_{2}$

Transfer hydrosilylation consists in the formal transfer of a hydrosilane moiety $\left(\mathrm{R}_{3} \mathrm{SiH}\right)$ from a silicon reagent (that bears no $\mathrm{Si}-\mathrm{H}$ bond) to a substrate. ${ }^{1}$ It is reminiscent of transfer hydrogenation where a hydrogen donor (e.g. isopropanol or formic acid) is used to deliver an equivalent of $\mathrm{H}_{2}$ to reduce a $\mathrm{C}=\mathrm{C}$ or $\mathrm{C}=\mathrm{O}$ unsaturation. ${ }^{2}$ Although the two methodologies are conceptually related, examples of transfer hydrosilylation reactions have only been disclosed recently with the use of silicon-substituted cyclohexa-1,4-dienes (1,4-CHDN) (1) able to deliver a hydrosilane equivalent with the concomitant release of a benzene derivative (Scheme 1). While Studer et al. explored the radical activation of these hydrosilane surrogates in the transfer hydrosilylation of alkenes, ${ }^{3-4}$ Oestreich et al. exploited their ionic activation for the transfer hydrosilylation of carbonyls, alcohols and alkenes. ${ }^{5-7}$ In 2016, Cantat et al. introduced a new type of hydrosilane surrogates with the use of silyl formates (2, $\mathrm{R}_{3} \mathrm{SiOCHO}$ ). ${ }^{8}$ While silyl formates are usually observed as products or intermediates in the hydrosilylation of $\mathrm{CO}_{2}, 9-12$ the reversible decarboxylation reaction was used to promote the transfer hydrosilylation of aldehydes (Scheme 1). ${ }^{8}$ An advantage of this methodology is the release of a gaseous by-product, $\mathrm{CO}_{2}$. Earlier this year, the same methodology was employed to convert alcohols to silyl ethers by dehydrogenative and decarboxylative silylation of $\mathrm{O}-\mathrm{H}$ bonds with silyl formates. ${ }^{13}$ Importantly, the use of silyl formates in transfer hydrosilylation reactions requires a catalyst able to promote the decarboxylation of a formate ligand and the silylation of alcohols and aldehydes could only be achieved using molecular ruthenium(II) complexes. ${ }^{8,13}$ Further utilization of silyl formates would strongly benefit from the use of noble metal free catalysts and, herein, we show for the first time that iron complexes, supported by a chelating tetraphosphine ligand, enable the silylation of alcohols by transfer hydrosilylation with silyl formates. An improved synthesis of silyl formates is also reported.

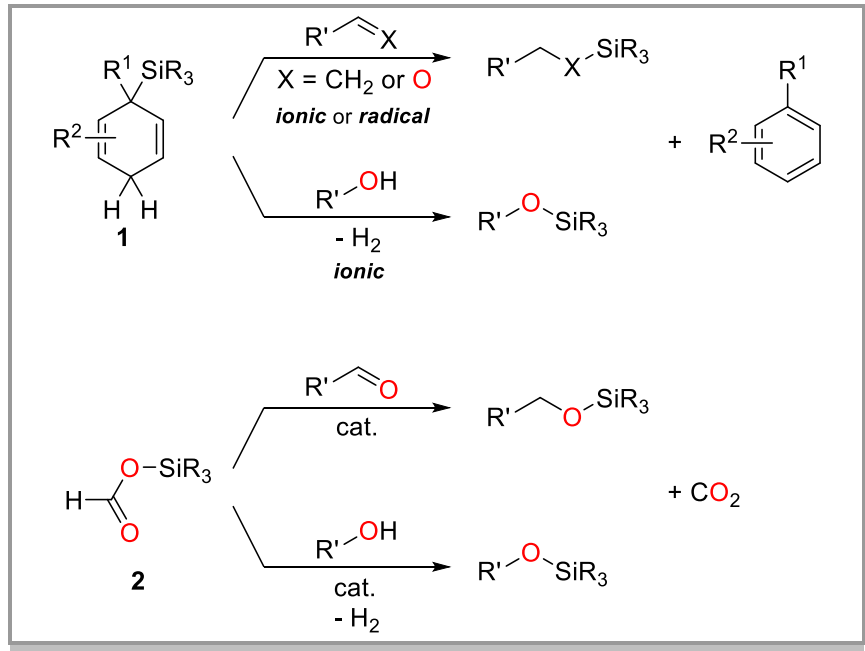

Scheme 1 Surrogates of hydrosilanes used in transfer hydrosilylation.

Although silyl formates can be obtained by catalytic hydrosilylation of $\mathrm{CO}_{2},{ }^{9-12}$ a more convenient access to these reagents relies on the silylation of formic acid with chlorosilanes, in the presence of an organic base, such as pyridine or triethylamine. ${ }^{8}$ Nevertheless, using this synthesis, free formic acid can be found as an impurity in samples of silyl formates and the presence of such protic species influences the catalytic activity in transfer hydrosilylation. To circumvent this limitation, a new route was exploited where chlorosilanes are reacted with 
sodium formate in ethereal solutions (Scheme 2). Heating a $\mathrm{Et}_{2} \mathrm{O}$ solution of $\mathrm{Et}_{3} \mathrm{SiCl}$ at $90^{\circ} \mathrm{C}$ in the presence of 1.4 equiv. $\mathrm{NaOCHO}$ after $12 \mathrm{~h}$, results in the formation of $\mathrm{Et}_{3} \mathrm{SiOCHO}$ (2a). After filtration aimed at removing the insoluble $\mathrm{NaCl}$ and $\mathrm{NaOCHO}$ precipitate and removal of the volatiles under reduced pressure, 2a was isolated in $94 \%$ yield. The procedure was successfully applied to the synthesis of a variety of silylformates, including trimethylsilyl (2b), tert-butyldimethylsilyl (TBDMS, 2c), diphenylmethylsilyl (DPMS, 2e), and phenyldimethylsilyl (PDMS, 2f) substituents. The yield is somewhat lower for $\mathbf{2 b}$ (82\%), compared to $\mathbf{2 c - 2} \mathbf{g}$ (92-99\%), because of the high volatility of the product and $\mathrm{TMSCl}$, and the reaction was carried out at $60^{\circ} \mathrm{C}$. The bulky triisopropylsilyl (TIPS) formate (2d) could not be obtained in satisfactorily yields and its synthesis was performed with formic acid, in the presence of triethylamine. ${ }^{8}$ Diethyldichlorosilane was efficiently converted to the bisformate derivative $\mathbf{2 g}$ ( $94 \%$ yield) upon reaction with an excess sodium formate (Scheme 2). Silyl formates $\mathbf{2 b}$ and to a lesser extent 2a were found to be sensitive towards moisture as they are readily hydrolyzed to formic acid and silanols and siloxanes.

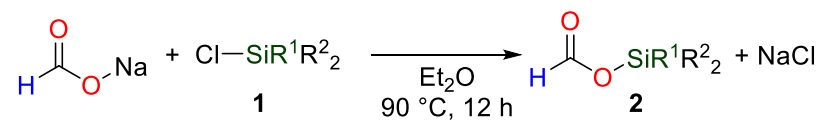

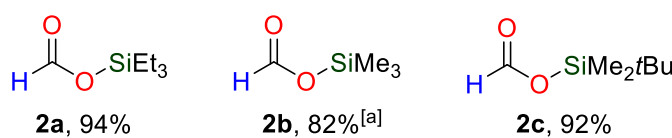

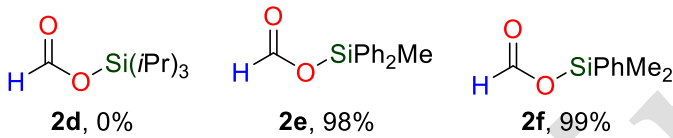

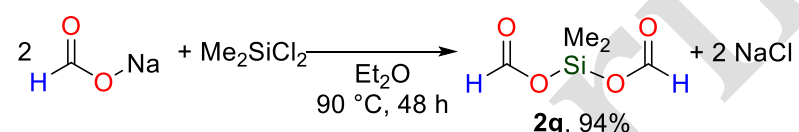

Scheme 2 Synthesis of silyl formates by salt metathesis from sodium formates and chlorosilanes. ${ }^{[a]} \mathrm{T}$ The reaction was performed at $60{ }^{\circ} \mathrm{C}$

Having in hand a collection of silyl formates bearing different alkyl and aryl substituents on the silicon center, their reactivity was evaluated in the dehydrogenative and decarboxylative silylation of alcohols. Silyl ethers are useful chemicals, utilized for the temporary protection of alcohols but also for the synthesis of hybrid materials. ${ }^{14-16}$ Two main routes have been developed to access the $\mathrm{O}-\mathrm{Si}$ linkage. They rely either on chlorosilanes or hydrosilanes. While the reaction between an alcohol and a chlorosilane, in the presence of a base, generates a stoichiometric amount of a salt, ${ }^{17-19}$ the catalytic dehydrogenative silylation with hydrosilanes has the advantage of releasing $\mathrm{H}_{2}$ gas as the only byproduct.20-26 This year, our group showed that replacing the hydrosilane reagent with a silyl formate enabled the silylation of a variety of alcohols when a catalytic amount of (triphos) $\mathrm{Ru}(\mathrm{OAc})_{2} \quad$ (triphos $\quad$ 1,1,1tris(diphenylphosphinomethyl)ethane) was added. ${ }^{13}$ The role of the $\mathrm{Ru}$ catalyst is to promote the decarboxylation of a formate ligand to yield a reactive hydride complex. Based on this assumption, we turned our attention to iron catalysts that are able to engage in similar reaction paths. In particular, Laurenczy, Ludwig, Beller et al. demonstrated the potential of iron(II) salts supported by the tetraphosphine ligand $\mathrm{P}_{2}\left(\mathrm{C}_{2} \mathrm{H}_{4} \mathrm{PPh}_{2}\right)_{3}$ (4, also labelled $\mathrm{PP}_{3}$ ) in the catalytic decomposition of formic acid to $\mathrm{H}_{2}$ and $\mathrm{CO}_{2}{ }^{27}$ Capitalizing on this work, the silylation of benzylalcohol (3) was attempted with $\mathrm{Et}_{3} \mathrm{SiOCHO}$ (2a), in the presence of $2 \mathrm{~mol} \% \mathrm{Fe}(\mathrm{OAc})_{2}$ and $2 \mathrm{~mol} \% 4$. After $5 \mathrm{~h}$ at $70{ }^{\circ} \mathrm{C}$ in $\mathrm{CH}_{2} \mathrm{Cl}_{2}$, the reagents were fully consumed and $\mathbf{5 a}$ was formed in quantitative yield (Scheme 3) [only $5 \% \mathbf{5 a}$ were observed in the absence of catalyst]. ${ }^{1} \mathrm{H}$ and ${ }^{13} \mathrm{C}$ NMR spectra of the crude mixture also confirmed the production of $\mathrm{H}_{2}$ and $\mathrm{CO}_{2}$ as by-products of the reaction. The formation of silyl ether $\mathbf{5 a}$ from $\mathbf{2 a}$ represents the second example of a dehydrogenative silylation of alcohols using silyl formates as surrogates of hydrosilanes. ${ }^{13}$ Although the reaction proceeded well in THF, acetonitrile or benzene, the best conversions were noticed in $\mathrm{CH}_{2} \mathrm{Cl}_{2}$ (see SI). Decreasing the reaction temperature to $25^{\circ} \mathrm{C}$ also enabled formation of $\mathbf{5 a}$ in $98 \%$ yield, after a prolonged reaction time of $21 \mathrm{~h}$. In comparison, (triphos)Ru(OAc) 2 was found inactive at room temperature (RT). ${ }^{13}$

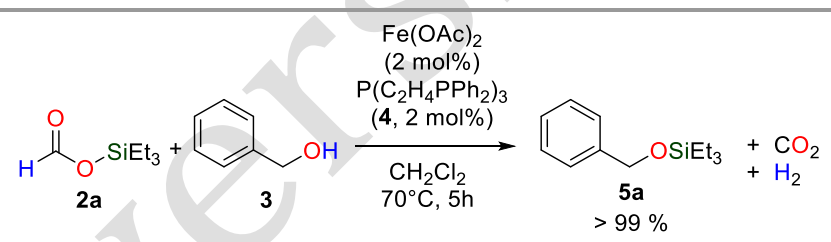

Scheme 3 Iron-catalyzed silylation of benzylalcohol (3) to $5 a$ with triethylsilyl formate (2a).

The influence of the silyl group was then investigated on the influence of the transfer hydrosilylation reaction. All the silyl formates $\mathbf{2 a - 2}$ g successfully reacted with $\mathbf{3}$ to yield silyl ethers $\mathbf{5 a - 5 g}$, respectively (Scheme 4). Full conversion of $\mathbf{3}$ was reached within $3 \mathrm{~h}$ at $70^{\circ} \mathrm{C}$ for the trimethylsilyl derivative $\mathbf{2 b}$ while the production of the more congested congeners $\mathbf{5 c}$ and $\mathbf{5 d}$, bearing TBDMS and TIPS groups, were limited to 56 and $34 \%$ yield, respectively, after $5 \mathrm{~h}$. Interestingly, the aryl-substituted silyl formates $\mathbf{2 e}$ and $\mathbf{2} \mathbf{f}$ and the bis-formate $\mathbf{2} \mathbf{g}$ were fully converted to the corresponding silyl ethers $\mathbf{5 e - 5 g}$ within only $1.5 \mathrm{~h}$, presumably because of the enhanced acidic character at the silicon center.

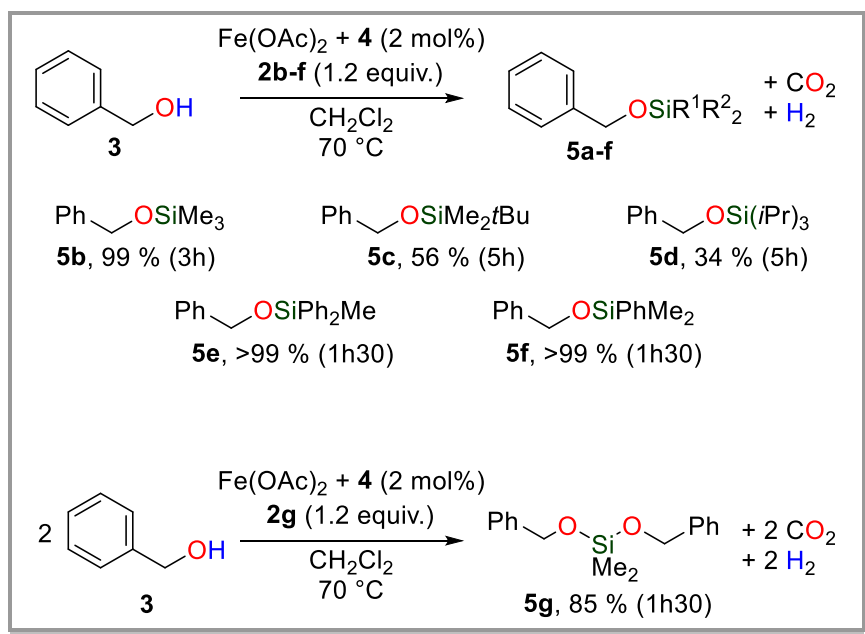

Scheme 4 Iron-catalyzed silylation of benzylalcohol (3) to 5 with silyl formates (2b-2g). 
The potential of the $\mathrm{Fe}(\mathrm{OAc})_{2} / 4$ catalytic system was further evaluated in the dehydrogenative and decarboxylative silylation of alcohols having various functional groups (Scheme 5). Aliphatic as well as aromatic alcohols were successfully silylated with $\mathrm{Et}_{3} \mathrm{SiOCHO}(\mathbf{2 a})$, as exemplified with the formation of $\mathbf{6 a}-$ 15a (from primary and secondary alcohols) and 17a-18a (from phenols). Primary and secondary alcohols exhibit similar reactivities as attested with the formation of silyl ethers $\mathbf{8 a}$ and 13a in $>96 \%$ yields from 2-phenyl-1-propanol and cycloheptanol, respectively. As such, the bis-silylation of the polyfunctional 1-phenyl-1,2-ethanediol to $\mathbf{2 0 b}$ is readily achieved with 2 equiv. 2b. Importantly, the method is also tolerant to oxidizing functional groups such as iodo, nitro, keto and vinyl groups (see $\mathbf{6 a}, \mathbf{7 a}, \mathbf{1 2 a}$, and $\mathbf{1 6} \mathbf{b}$ ). For example, despite the reductive conditions imposed by the combination of silyl formate $\mathbf{2 b}$ and the $\mathrm{Fe}(\mathrm{OAc})_{2} / \mathbf{4}$ catalyst, the silylation of testosterone to $\mathbf{1 6 b}$ is carried out in $92 \%$ yield within $2 \mathrm{~h}$ without reduction of the enone functionality. Overall, the $\mathrm{Fe}(\mathrm{OAc})_{2} / 4$ presents a catalytic activity and a reaction scope very similar to (triphos) $\mathrm{Ru}(\mathrm{OAc})_{2}$, with the benefit of utilizing a first row transition metal complex. This is further confirmed with the isolation of silyl ester 21a that can be obtained from the silylation of benzoic acid with $\mathbf{2 a}$ and either the iron or ruthenium catalyst. ${ }^{13}$

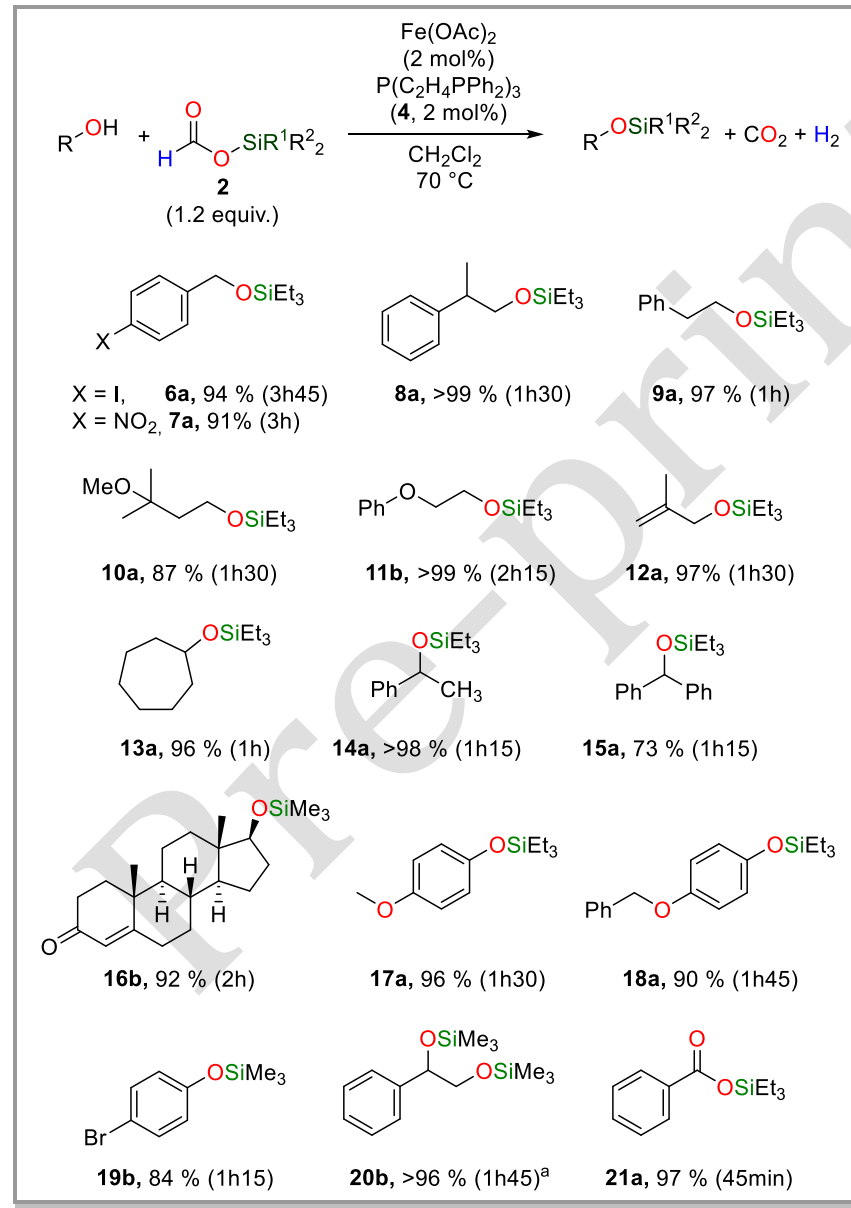

Scheme 5 Scope of the transfer dehydrogenative silylation of alcohols with silyl formates. Reaction conditions: alcohol $(0.50 \mathrm{mmol})$, silyl formate $(0.60 \mathrm{mmol})$, $\mathrm{Fe}(\mathrm{OAc})_{2}(2 \mathrm{~mol} \%), 4(2 \mathrm{~mol} \%), \mathrm{CH}_{2} \mathrm{Cl}_{2}(2.0 \mathrm{~mL} ; 0.25 \mathrm{M}) ; 70{ }^{\circ} \mathrm{C}$. Isolated yields are provided for reaction times indicated in brackets. [a]The stoichiometry was adapted with the use of $1.2 \mathrm{mmol} 2 \mathrm{a}$.
Preliminary mechanistic investigations with (triphos) $\mathrm{Ru}(\mathrm{OAc})_{2}$ have shown that the silylation of alcohols with silyl formates results from a two-step process where the metal complex first catalyzes a trans-silylation equilibrium between the reagents to yield the corresponding silyl ether and free formic acid. ${ }^{13}$ The ruthenium plays a second role by catalyzing the irreversible decomposition of formic acid to $\mathrm{H}_{2}$ and $\mathrm{CO}_{2}$, thereby driving the production of silyl ether to completion. The transient formation of free formic acid was observed by ${ }^{1} \mathrm{H}$ NMR spectroscopy upon silylation of $\mathbf{3}$ with silyl formate $\mathbf{2 a}$ and $\mathrm{Fe}(\mathrm{OAc})_{2} / \mathbf{4}$ (Scheme 3), suggesting that the iron catalyst follows a similar reaction path. The hypothesis was further confirmed as $\mathrm{Fe}(\mathrm{OAc})_{2} / 4$ readily dehydrogenates formic acid to $\mathrm{H}_{2}$ and $\mathrm{CO}_{2}$, at $90^{\circ} \mathrm{C}$ under basefree conditions in $\mathrm{CH}_{2} \mathrm{Cl}_{2}$ (see SI). To gain deeper insights into the nature of the active iron(II) species, the stoichiometric reaction between $\mathrm{Fe}(\mathrm{OAc})_{2}, 4$ and 2 equiv. $\mathrm{Et}_{3} \mathrm{SiOCHO}$ (2a) was carried out in $\mathrm{CH}_{2} \mathrm{Cl}_{2}$ at $70{ }^{\circ} \mathrm{C}$. Rapid gas evolution indicated the transformation of the iron acetate complex. Isolation of the resulting iron complex by recrystallization from $\mathrm{CH}_{2} \mathrm{Cl}_{2}$ /pentane enabled the structure determination of $\mathbf{2 2}$ by X-ray diffraction (Figure 1). 22 is an 18-electron iron(II) hydrido chloro complex supported by the tetraphosphine ligand 4 , coordinated with a $\kappa-$ 4 mode. ${ }^{28-29}$ The formation of $\mathbf{2 2}$ demonstrates the ability of $\mathrm{Fe}(\mathrm{OAc})_{2} / 4$ to yield iron-hydride species in the presence of silyl formates and this chemical behaviour is consistent with previous findings from Beller et al. on the reactivity of iron(II) complexes supported by 4 in the presence of formic acid. ${ }^{30}$

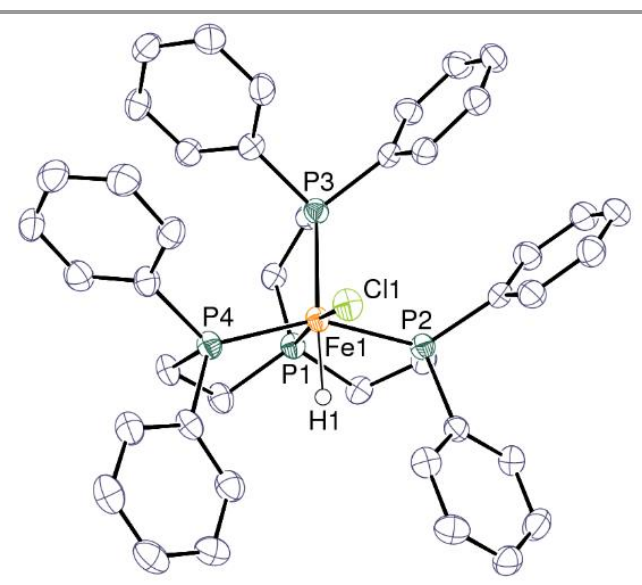

Figure 1 View of complex 22 ([Fe(4) HCl]). Displacement ellipsoids are drawn at the $50 \%$ probability level and carbon-bound hydrogen atoms are omitted.

The catalytic implication of $\mathbf{2 2}$ was tested in the silylation of $\mathbf{3}$. As expected, 22 possesses a catalytic activity similar to $\mathrm{Fe}(\mathrm{OAc})_{2} / 4$ and the complex promotes the formation of $\mathbf{5 a}$ in the reaction described in Scheme 3. Based on these data, a mechanistic proposal is drawn in Scheme 6: an active iron(II) hydride species (likely 22) is formed from $\mathrm{Fe}(\mathrm{OAc})_{2}$ in the presence of 4 and the silyl formate reductant. The complex is then able to decompose $\mathrm{HCO}_{2} \mathrm{H}$ by successive dehydrogenation and decarboxylation steps, in order to displace the equilibrium involving the alcohol, the silyl ether, and free formic acid to the formation of the silyl ether product. 


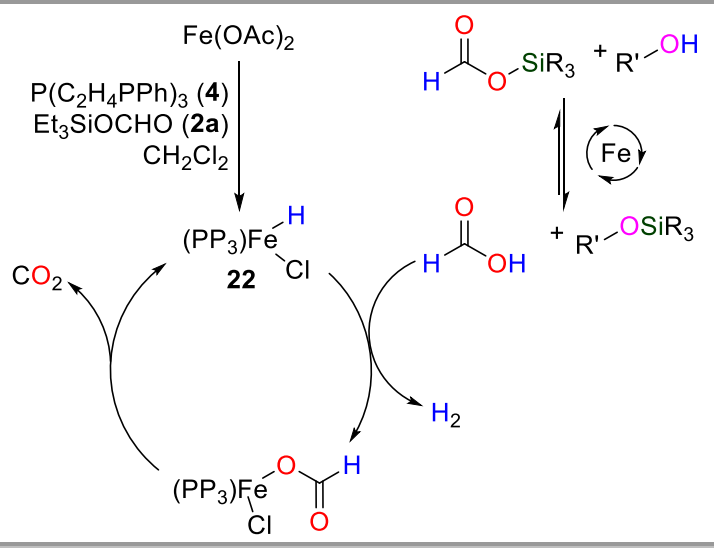

Scheme 5 Proposed mechanism for the dehydrogenative and decarboxylative coupling of alcohols and silyl formates catalysed by $\mathrm{Fe}(\mathrm{OAc})_{2} / 4$.

In conclusion, we have described an efficient synthetic route for the synthesis of silyl formates from chlorosilanes and sodium formates and the first iron catalysts able to utilize silyl formates as surrogates of hydrosilanes. ${ }^{31} \mathrm{Fe}(\mathrm{OAc})_{2}$, supported by $\mathrm{P}\left(\mathrm{C}_{2} \mathrm{H}_{4} \mathrm{PPh}_{2}\right)_{3}$ (4), is an efficient catalyst for the dehydrogenative and decarboxylative silylation of alcohols to silyl ethers. The iron catalyst exhibits a catalytic behaviour similar to (triphos) $\mathrm{Ru}(\mathrm{OAc})_{2}$ in this reaction and was shown to produce iron-hydride species in dichloromethane, in the presence of silyl formates. Further efforts are underway in our laboratories to exploit the reducing ability of such intermediates in new transfer hydrosilylation reactions.

\section{Funding Information}

For financial support of this work, we acknowledge CEA, CNRS, the CHARMMMAT Laboratory of Excellence and the European Research Council (ERC Starting Grant Agreement n.336467). T.C. thanks the Foundation Louis D. - Institut de France for its support.

\section{Acknowledgment}

Click here to insert acknowledgment text. Funding sources and grant numbers should be given above in the Funding Information section.

\section{Supporting Information}

YES (this text will be updated with links prior to publication)

\section{Primary Data}

NO (this text will be deleted prior to publication)

\section{References and Notes}

1. Oestreich, M., Angew. Chem. Int. Ed. 2016, 55, 494-499.

2. Wang, D.; Astruc, D., Chem. Rev. 2015, 115, 6621-6686.

3. Amrein, S.; Studer, A., Helv. Chim. Acta 2002, 85, 3559-3574.

4. Amrein, S.; Timmermann, A.; Studer, A., Org. Lett. 2001, 3, $2357-$ 2360.

5. Keess, S.; Simonneau, A.; Oestreich, M., Organometallics 2015, 34, 790-799.

6. Simonneau, A.; Oestreich, M., Angew. Chem. Int. Ed. 2013, 52, 11905-11907.

7. Simonneau, A.; Oestreich, M., Nature Chem. 2015, 7, 816-822.

8. Chauvier, C.; Thuery, P.; Cantat, T., Angew. Chem. Int. Ed. 2016, 55, 14096-14100.
9. Lalrempuia, R.; Iglesias, M.; Polo, V.; Miguel, P. J. S.; FernandezAlvarez, F. J.; Perez-Torrente, J. J.; Oro, L. A., Angew. Chem. Int. Ed. 2012, 51, 12824-12827.

10. Motokura, K.; Kashiwame, D.; Takahashi, N.; Miyaji, A.; Baba, T., Chem. Eur. J. 2013, 19, 10030-10037.

11. Sattler, W.; Parkin, G., J. Am. Chem. Soc. 2012, 134, 17462-17465.

12. Zhang, L.; Cheng, J. H.; Hou, Z. M., Chem. Commun. 2013, 49, 4782-4784.

13. Chauvier, C.; Godou, T.; Thuéry, P.; Cantat, T., Chem. Commun. 2017, DOI: 10.1039/C7CC05212J.

14. P. G. M. Wuts and T. W. Greene, in Greene's Protective Groups in Organic Synthesis, John Wiley \& Sons, Inc., 2006, pp. 16-366.

15. Huang, C. H.; Ghavtadze, N.; Chattopadhyay, B.; Gevorgyan, V., J. Am. Chem. Soc. 2011, 133, 17630-17633.

16. Herrera, N. N.; Letoffe, J. M.; Putaux, J. L.; David, L.; BourgeatLami, E., Langmuir 2004, 20, 1564-1571.

17. Patschinski, P.; Zhang, C.; Zipse, H., J Org Chem 2014, 79, 83488357.

18. Corey, E. J.; Venkateswarlu, A., J Am Chem Soc 1972, 94, 6190-+.

19. Corey, E. J.; Cho, H.; Rucker, C.; Hua, D. H., Tetrahedron Lett. 1981, 22, 3455-3458.

20. Mukherjee, D.; Thompson, R. R.; Ellern, A.; Sadow, A. D., ACS Catal. 2011, 1, 698-702.

21. Garces, K.; Fernandez-Alvarez, F. J.; Polo, V.; Lalrempuia, R.; Perez-Torrente, J. J.; Oro, L. A., ChemCatChem 2014, 6, 1691-1697. 22. Weickgenannt, A.; Oestreich, M., Chem.-Asian J. 2009, 4, 406410.

23. Chang, S.; Scharrer, E.; Brookhart, M., J. Mol. Catal. A-Chem. 1998, 130, 107-119.

24. Blackwell, J. M.; Foster, K. L.; Beck, V. H.; Piers, W. E., J. Org. Chem. 1999, 64, 4887-4892.

25. Ito, H.; Watanabe, A.; Sawamura, M., Org. Lett. 2005, 7, 18691871.

26. Toutov, A. A.; Betz, K. N.; Haibach, M. C.; Romine, A. M.; Grubbs, R. H., Org. Lett. 2016, 18, 5776-5779.

27. Boddien, A.; Mellmann, D.; Gartner, F.; Jackstell, R.; Junge, H.; Dyson, P. J.; Laurenczy, G.; Ludwig, R.; Beller, M., Science 2011, 333, 1733-1736.

28. Field, L. D.; Messerle, B. A.; Smernik, R. J., Inorg. Chem. 1997, 36, 5984-5990.

29. Field, L. D.; Messerle, B. A.; Smernik, R. J.; Hambley, T. W.; Turner, P., Inorg. Chem. 1997, 36, 2884-2892.

30. Mellmann, D.; Barsch, E.; Bauer, M.; Grabow, K.; Boddien, A.; Kammer, A.; Sponholz, P.; Bentrup, U.; Jackstell, R.; Junge, H.; Laurenczy, G.; Ludwig, R.; Beller, M., Chem. Eur. J. 2014, 20, 1358913602.

31. General procedure for the synthesis of silylformates (2) In a glovebox, a flame-dried round bottom flask equipped with a Solv-seal connection and a J-Young valve was charged with sodium formate (42 mmol, 1.4 equiv.) and suspended in diethyl ether (30 $\mathrm{mL}, \mathrm{C}=1 \mathrm{M}$ ). To the resulting suspension was added the silyl chloride ( $30 \mathrm{mmol}, 1$ equiv.). The flask was then sealed, brought out of the glovebox and immersed in a pre-heated oil bath at $90{ }^{\circ} \mathrm{C}$ (oil temperature). Unless otherwise stated, the reactions were generally complete within $15 \mathrm{~h}$. The mixture was then filtered over a sintered glass funnel and the solvent removed by distillation under vacuum at $0{ }^{\circ} \mathrm{C}$. No other purification was needed. The formation of silyl formate was confirmed by $1 \mathrm{H}, 13 \mathrm{C}$ NMR and elemental analysis. 
Analytical data for $\mathbf{2 e}$ is provided below, as a representative example:

${ }^{1} \mathrm{H}$ NMR (200 MHz, $d_{8}$-THF) $\delta 8.18(\mathrm{~s}, 1 \mathrm{H}), 7.71-7.56(\mathrm{~m}, 4 \mathrm{H}), 7.38$ (m, 6H), 0.85 (s, 3H). ${ }^{13} \mathrm{C}$ NMR (50 MHz, $d_{8}$-THF) $\delta 160.88,135.09$, $134.47,130.99,128.53,-2.64$. Elemental Analysis: calcd (\%) for $\mathrm{C}_{14} \mathrm{H}_{14} \mathrm{O}_{2} \mathrm{Si}$ (243.3 g.mol-1): C 69.39, H 5.82, found: C 69.03, H 5.67.

\section{General procedure for the transfer hydrosilylation of alcohols} with silylformates (5-21)

In a glovebox, a flame-dried flask equipped with a J-Young valve was charged with $\mathrm{Fe}(\mathrm{OAc})_{2}(1.7 \mathrm{mg}, 0.01 \mathrm{mmol}, 2 \mathrm{~mol} \%)$ and $\mathrm{P}\left(\mathrm{C}_{2} \mathrm{H}_{4} \mathrm{PPh}_{2}\right)_{3}$ (4) (6.7 mg , $0.01 \mathrm{mmol}, 2 \mathrm{~mol} \%$ ) followed by $\mathrm{CH}_{2} \mathrm{Cl}_{2}$ $(2 \mathrm{~mL}, \mathrm{C}=0.25 \mathrm{M})$. To the resulting white suspension were sequentially added the alcohol ( $0.5 \mathrm{mmol}, 1$ equiv.) and the silyl formate ( $0.6 \mathrm{mmol}, 1.2$ equiv. per hydroxyl group) reagents. The flask was then sealed, brought out of the glovebox and immersed in a pre-heated oil bath at $90^{\circ} \mathrm{C}$ (oil temperature). A purple coloration appeared when heated. At this temperature, all the reactions were generally complete within $1.5 \mathrm{~h}$ with silyl formates 2 . The coloration observed turned from purple to bright orange. Yields of silyl ethers were determined after isolation and purification by column chromatography on silica gel.

Analytical data for $\mathbf{1 6 b}$ is provided below, as a representative example:

${ }^{1} \mathrm{H}$ NMR (200 MHz, $d_{8}$-THF) $\delta 5.59(\mathrm{~s}, 1 \mathrm{H}), 3.58(\mathrm{~m}, 2 \mathrm{H}), 1.89(\mathrm{~m}$, 14H), 1.20 (s, 3H), $1.12-0.78(\mathrm{~m}, 4 \mathrm{H}), 0.75$ (s, 3H), 0.06 (s, 9H). ${ }^{13} \mathrm{C}$ NMR $\left(50 \mathrm{MHz}, d_{8}\right.$-THF) $\delta 195.30,167.91,122.75,80.52,53.42$, 49.26, 41.92, 37.52, 35.86, 35.00, 34.79, 32.75, 31.49, 30.85, 29.81, $22.38,19.69,15.74,9.80,-1.61$. HRMS (ESI) $\mathrm{m} / \mathrm{z}[\mathrm{M}+\mathrm{H}]+$ calcd. for $\mathrm{C}_{14} \mathrm{H}_{25} \mathrm{O}_{2} \mathrm{Si}^{+}$361.2557; found : 361.2557 . 